\title{
Electrophoretic Study on a Soluble Complex of Heparin and Fibrinogen
}

\author{
Eiji NaKanishi, ${ }^{*}$ Hiroko Sato, ${ }^{\dagger}$ and Akio NaKaJima** \\ Department of Polymer Chemistry, Kyoto University, Sakyo-ku, Kyoto 606
}

(Received October 13, 1989)

\begin{abstract}
The formation of a soluble complex of heparin and fibrinogen was observed in $0.05 \mathrm{M}$ phosphate buffer at $\mathrm{pH} 7.0$ in low ionic strength at $5^{\circ} \mathrm{C}$. That is, the electrophoretic mobility, slightly depending on heparin concentrations, of the complex was faster than that of fibrinogen, and slower than that of heparin. Quantitative analysis on the complex was carried out by using the free boundary electrophoresis. In the soluble complex, heparin was regarded to be bound reversibly with fibrinogen and adsorbed to fibrinogen in the mode of the Freundlich adsorption isotherm. The dissociation constant between heparin and fibrinogen was evaluated to be $7.4 \times 10^{-4} \mathrm{M}$, so that the interaction in the soluble complex with fibrinogen was considered to be too loose to contribute toward the anticoagulant activity of heparin.

KEY WORDS Free Boundary Electrophoresis / Soluble Complex / Electrophoretic Mobility / Heparin / Fibrinogen / Freundlich Adsorption Isotherm / Binding Constant / Anticoagulant Activity /
\end{abstract}

Heparin is well-known to be a biologically multifunctional molecule, interacting not only various cells but such diverse proteins as are participated in coagulation, adhesion, lipolysis, and so on Particularly, heparin forms a complex with antithrombin III, ${ }^{1}$ and acts as an extremely potent inhibitor against activated coagulant factors of serine proteases. However, interactions with plasma adhesive proteins such as fibronectin, ${ }^{2}$ vitronectin, ${ }^{3}$ thrombospondin, ${ }^{2}$ von Wilbrand factor, ${ }^{4}$ and etc., which have heparin-binding domains, lead to increase the administration amount of heparin necessary for the anticoagulant therapy. On the other hand, fibrinogen, a coagulable protein and one of adhesive proteins, is contained in much higher concentrations in plasma than above-written adhesive proteins.

Heparin, a polyanion with relatively high charge density, was observed to form various complexes. That is, heparin was found to form a soluble complex with albumin. ${ }^{5,6}$ According to Porter et al., ${ }^{7}$ however, heparin formed no stable complexes with albumin and fibrinogen. From the electrophoretic measurement, ${ }^{8}$ heparin was suggested to form a soluble complex with fibrinogen in plasma at $\mathrm{pH}$ 8.6. Moreover, Godal $^{9}$ also found that heparin bound to fibrinogen, whereby spontaneous precipitates were formed in a buffer of low ionic strength (below 0.01) at $\mathrm{pH}$ below 7.0. Thus, it is important to study on the interaction between heparin and fibrinogen, although it seems weak at neutral $\mathrm{pH}$, even if it exists.

* Present address: Department of Materials Science and Engineering, Nagoya Institute of Technology, Gokiso-cho, Showa-ku, Nagoya 466, Japan.

** Present address: Department of Applied Chemistry, Osaka Institute of Technology, Ohmiya, Asahi-ku, Osaka 535 , Japan.

† To whom correspondence should be addressed. Present address: Research Center for Medical Polymers and Biomaterials, Kyoto Univrsity, 53 Kawaharacho, Shogoin, Sakyo-ku, Kyoto 606, Japan. 
Many acidic polysaccharides, different from heparin, with high charge density and high molecular weight were observed to cause solid-liquid phase separation and to form polyion complexes ${ }^{10}$ with fibrinogen at $\mathrm{pH} 7.0$ and at low ionic strength. Although the whole fibrinogen molecule is charged negatively at $\mathrm{pH}$ 7.0, positively charged microdomains which are localized on fibrinogen, should play a role in the formation of polyion complexes. The purpose of this work is to study quantitatively on interaction of heparin and fibrinogen in $0.05 \mathrm{M}$ phosphate buffer at neutral $\mathrm{pH}$ by using the free boundary electrophoresis and to relate it with interactions of heparin and some plasma proteins.

\section{EXPERIMENTAL}

\section{Materials}

Bovine fibrinogen, 95\% clottable, was purchased from Miles Lab. Inc. (Lot 24). Heparin, sodium salt, (Lot. M6G5365) was obtained from Nakarai Chemical Co., and had anticoagulant activities of 152 units $\mathrm{mg}^{-1}$ solid. The molecular weight was estimated as 9000 from the viscometric measurement by using the relation reported by Lasker and Stivala $^{11}$ and the number of anionic groups per pyranose unit was estimated as $1.5 .^{10}$

\section{Samples for Electrophoresis}

Fibrinogen was slowly dissolved in $0.05 \mathrm{M}$ phosphate buffer without stirring and $c a$. $1.2 \mathrm{~g} \mathrm{dl}^{-1}$ fibrinogen solution was clarified by filtration through a Millipore HA filter with the pore size of $10 \mu \mathrm{m}$. The fibrinogen solution was kept for $10 \mathrm{~h}$ in a refrigerator to remove the cyrofibrinogen ${ }^{12}$ precipitated at low temperature. The supernatant solution was placed into a cellulose tube (membrane cut off $M_{\mathrm{r}}, 10000$ ) and dialysed against $0.05 \mathrm{M}$ phosphate buffer at $5^{\circ} \mathrm{C}$ for $24 \mathrm{~h}$. After dialysis, the concentration of fibrinogen solution as determined spectrophotometrically at $280 \mathrm{~nm}$ with a Hitachi Model EPS-3T spectrophotometer by using the extinction coefficient ${ }^{8}$ of 1.506 for $0.1 \mathrm{~g} \mathrm{dl}^{-1}$ fibrinogen and $1 \mathrm{~cm}$ light path. The concentration of cryofibrinogen, precipitated at low temperature, estimated spectrophotometrically to be less than $10 \%$.

Heparin was dissolved in $0.05 \mathrm{M}$ phosphate buffer at $\mathrm{pH} 7.0$ and 0.106 of ionic strength in the concentration range from 0.05 to $1.0 \mathrm{~g} \mathrm{dl}^{-1}$, and dialyzed against $0.05 \mathrm{M}$ phosphate buffer by using a cellulose tube (membrane cut off $M_{\mathrm{r}}, 3000$ ) at $5^{\circ} \mathrm{C}$ for $24 \mathrm{~h}$. Mixtures of fibrinogen and heparin were prepared by mixing the dialyzed fibrinogen solution with a dialyzed heparin solution at various mixing ratios.

\section{Electrophoresis}

Electrophoresis experiments were carried out by means of a Hitachi free boundary Tiselius apparatus HTB-2A, equipped with a schlierendiagonal optical system. A $2 \mathrm{ml}$ Tiselius cell of the electrophoresis apparatus was kept at $5.0 \pm 0.05^{\circ} \mathrm{C}$ in a water bath so as to expect less effects of molecular diffusion on the measurement. The conductivity of solution was measured at $5.0^{\circ} \mathrm{C}$ by using a Yanagimoto conductivity outfit Model MY-8. A sample solution was filled in descending and connecting parts of a Tiselius cell. The photographs were taken on a Polaroid $4 \times 5 \mathrm{~cm}$ land film (Type 55 Positive/Negative). In addition to a photograph of the initial boundary, 10 photographs of both the descending and ascending sides were taken during the process of electrophoresis. Electrophoretic mobilities and peak areas were analyzed on the negative films, enlarged by 20 times by using a Nikon profile projector $6 \mathrm{C}-2$.

When one component moves $d \mathrm{~cm}$ during $t \mathrm{~s}$ at a field strength $E$ (volt $\mathrm{cm}^{-1}$ ), the electrophoretic mobility $u\left(\mathrm{~cm}^{2}\right.$ volt $\left.{ }^{-1} \mathrm{~s}^{-1}\right)$ is represented by

$$
u=\frac{d}{t E}=\frac{d \kappa S}{i t}
$$

where $\kappa$ is the specific conductivity $\left(\mathrm{ohm}^{-1}\right.$ 
$\left.\mathrm{cm}^{-1}\right), S$ is the cross-sectional area of the cell, and $i$ is the amperage.

When a component in a mixture is migrated and the corresponding peak is sufficiently separated from other peaks, the area of $a$ component $\left(A_{a}\right)$ is obtained by integrating both right and left sides $\left(x_{1}, x_{2}\right)$ of its peak, and the concentration gradient $\mathrm{d} c / \mathrm{d} x$ is proportional to the refractive index gradient $\mathrm{d} n / \mathrm{d} x$. Thus $A_{a}$ is expressed by

$$
A_{a}=\int_{x_{1}}^{x_{2}}(\mathrm{~d} n / \mathrm{d} x) \mathrm{d} x=\int_{x_{1}}^{x_{2}} k_{a}\left(\mathrm{~d} c_{a} / \mathrm{d} x\right) \mathrm{d} x=k_{a} c_{a}
$$

where $k_{a}$ is the refractive index increment $\mathrm{d} n_{a} / \mathrm{d} c$ of the $a$ component, and $c_{a}\left(\mathrm{~g} \mathrm{dl}^{-1}\right)$ indicates the concentration of the $a$ component.

\section{RESULTS AND DISCUSSION}

\section{Electrophoresis for a Single Component of Fibrinogen or Heparin}

Schlieren patterns of fibrinogen (Fbg) and heparin (Hep) are shown in Figure 1(a) and (b), respectively. Fibrinogen migrated as a symmetrical sharp single peak. Since the schieren pattern of a fibrinogen solution at $5^{\circ} \mathrm{C}$ was identical to one, measured at $20^{\circ} \mathrm{C}$, of fibrinogen after dialysis at room temperature, cryofibrinogen seems to have the similar mobility as fibrinogen.

Heparin had a single asymmetric broad peak until the migration time of $15 \mathrm{~min}$, and then a slower peak appeared on the ascending side at $40 \mathrm{~min}$. A faster peak of heparin solutions, however, did not migrate distinguishably from the main peak of the mobility $\left(1.9 \times 10^{-5} \mathrm{~cm}^{2}\right.$ $\mathrm{s}^{-1} \mathrm{~V}^{-1}$ ) in the descending side (Table I). Heparin used, however, does not mean to consist of two species. Because it is well-known that commercial heparin preparations, derived from various sources, are composed of species which have a broad molecular weight distribution $^{14}$ and electrophoretic properties as well as anticoagulant activities. ${ }^{15,16}$

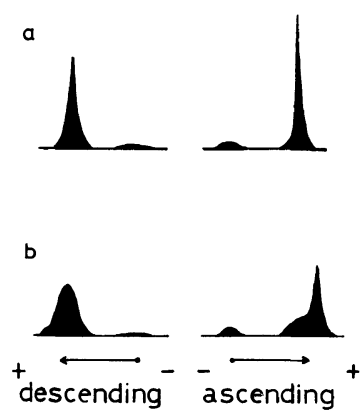

Figure 1. Electrophoresis schlieren patterns of fibrinogen ( $\mathrm{Fbg}$ ) (a), and heparin (Hep) (b). The starting point of the arrow expresses the position of the initial boundary. $[\mathrm{Fbg}]=0.75 \mathrm{~g} \mathrm{dl}^{-1}$, field strength $=5.04 \mathrm{~V} \mathrm{~cm}^{-1}$, and migration time $120 \mathrm{~min}$. (b) $[\mathrm{Hep}]=1.00 \mathrm{~g} \mathrm{dl}^{-1}$, field strength $=$ $5.21 \mathrm{~V} \mathrm{~cm}^{-1}$, and migration time $=35 \mathrm{~min}$. [ ] indicate concentration.

Electrophoresis of Mixtures for Fibrinogen and Heparin

Electrophoresis of mixtures were measured for fibrinogen at a fixed concentration, $0.375 \mathrm{~g} \mathrm{dl}^{-1}$, and heparin in the concentration range from 0.25 to $0.50 \mathrm{~g} \mathrm{dl}^{-1}$. Schlieren patterns of a mixture are changed with migration time as is obvious in Figure 2. After 4 min migration, precipitates, shutting off the light, occurred in the descending side, which resulted in a black stripe in the schlierent pattern. The width of the precipitate stripe was spreaded with migration time, although precipitates disappeared by the removal from an electric field. Thus, detailed investigation on the complex formation was carried out on the analysis of schlieren patterns in the ascending side.

Numerical values for the electrophoretic mobility of two peaks of heparin, fibrinogen, and mixtures of fibrinogen and heparin are summarized in Table $I$. The mobility of fibrinogen or heparin in a single component solution exhibits a definite value each in the ascending or in the descending side, while mobility values for components in mixtures decrease slightly with decreasing concentrations of heparin in the ascending side. In a mixture of fibrinogen and heparin, fast 
Soluble Complex of Heparin and Fibrinogen

Table I. Electrophoretic mobility $u$ of peaks in fibrinogen, heparin, and mixtures of fibrinogen and heparin

\begin{tabular}{|c|c|c|c|c|c|}
\hline \multirow{2}{*}{$\frac{\text { Fibrinogen }}{\mathrm{g} \mathrm{dl}^{-1}}$} & \multirow{2}{*}{$\begin{array}{c}\text { Heparin } \\
\mathrm{g} \mathrm{dl}^{-1}\end{array}$} & \multicolumn{4}{|c|}{$-u \times 10^{-5}, \mathrm{~cm}^{2} \mathrm{~s}^{-1} \mathrm{~V}^{-1}$} \\
\hline & & \multicolumn{2}{|c|}{ Ascending } & \multicolumn{2}{|c|}{ Descending } \\
\hline \multicolumn{6}{|c|}{ (Single component) } \\
\hline 0.75 & 0 & $2.9 \pm 0.1$ & & $2.3 \pm 0.1$ & \\
\hline 0.375 & 0 & $2.8 \pm 0.1$ & & $2.4 \pm 0.1$ & \\
\hline 0 & 1.00 & & $\begin{array}{c}25 \pm 0.5 \\
21 \pm 0.5\end{array}$ & & $19 \pm 0.5$ \\
\hline 0 & 0.75 & & $\begin{array}{c}24 \pm 0.5 \\
20 \pm 0.5\end{array}$ & & $19 \pm 0.5$ \\
\hline 0 & 0.50 & & $\begin{array}{l}24 \pm 0.5 \\
20 \pm 0.5\end{array}$ & & $\begin{array}{c}19 \pm 0.5 \\
-\end{array}$ \\
\hline \multicolumn{6}{|l|}{ (Mixtures) } \\
\hline 0.375 & 0.50 & $9.3 \pm 0.3$ & $\begin{array}{c}2.4 \pm 0.5 \\
20 \pm 0.5\end{array}$ & $(9.2)^{\mathrm{a}}$ & $\begin{array}{l}21 \pm 0.5 \\
17 \pm 0.5\end{array}$ \\
\hline 0.375 & 0.375 & $9.1 \pm 0.3$ & $\begin{array}{l}23 \pm 0.5 \\
20 \pm 0.5\end{array}$ & $(9.2)^{\mathrm{a}}$ & $\begin{array}{l}21 \pm 0.5 \\
18 \pm 0.5\end{array}$ \\
\hline 0.375 & 0.25 & $8.8 \pm 0.3$ & $\begin{array}{l}23 \pm 0.5 \\
19 \pm 0.5\end{array}$ & $(9.2)^{\mathrm{a}}$ & $\begin{array}{l}21 \pm 0.5 \\
18 \pm 0.5\end{array}$ \\
\hline
\end{tabular}

a Estimated from the middle point of a migrating opaque stripe, correponding to precipitates.

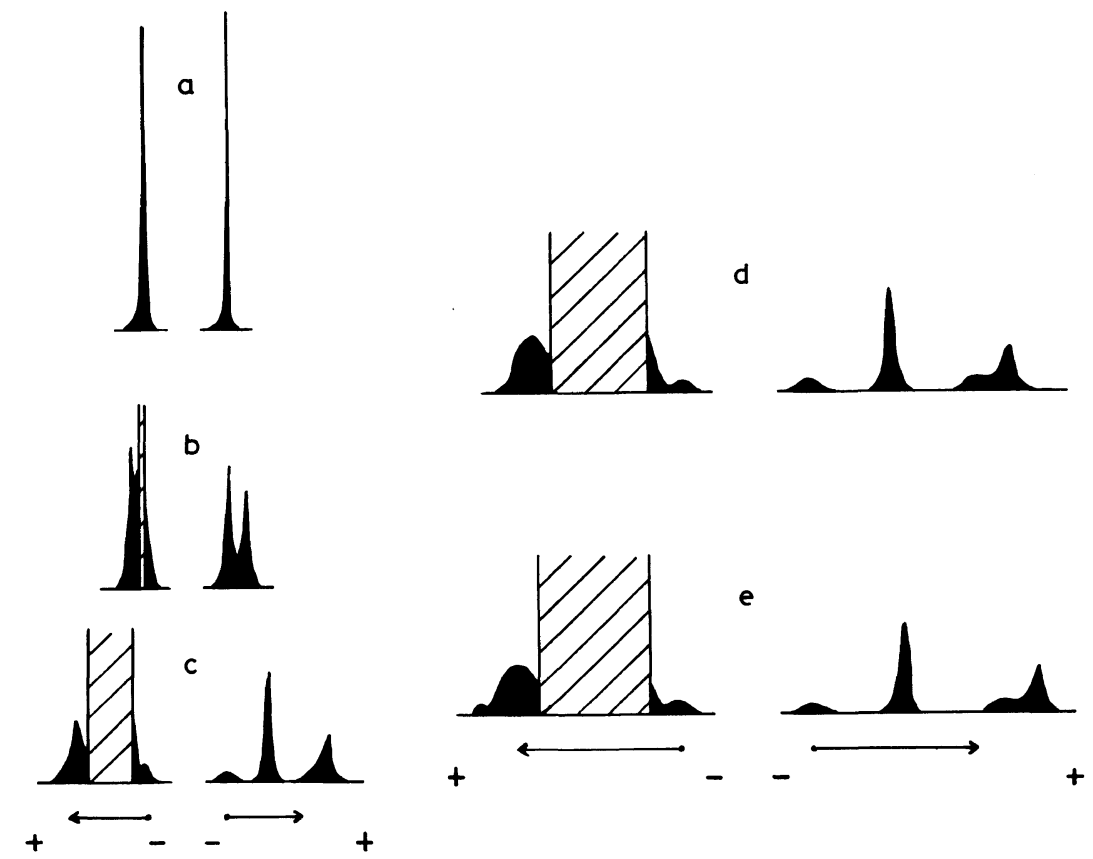

Figure 2. Migration of electrophoresis schlieren patterns of a mixture of $0.375 \mathrm{~g} \mathrm{dl}^{-1}$ fibrinogen and $0.50 \mathrm{~g} \mathrm{dl}^{-1}$ heparin at the initial boundary (a), $4 \mathrm{~min}(\mathrm{~b}), 20 \mathrm{~min}$ (c), $40 \mathrm{~min}$ (d), and $45 \mathrm{~min}$ (e). 
asymmetric peaks in the ascending side should be attributed to heparin because of almost the same mobility numerals as ones of heparin. In addition, the schlieren patterns were similar to ones of heparin in shape, dependent on migration time.

The mobility, $-u=8.8-9.3 \times 10^{-5} \mathrm{~cm}^{2} \mathrm{~s}^{-1}$ $\mathrm{V}^{-1}$, of the other peak is considerably larger than that of fibrinogen (Table I). Therefore, heparin molecules seem to bind fibrinogen, resulting in the larger mobility of a newly formed complex with fibrinogen in the ascending side. On the other hand, the opaque zone was formed reversibly in the descending side, dependent on an electric field. The precipitates owing to complex formation may be attributed to the lack in sufficient amount of heparin ${ }^{17}$ which had much faster mobility than the complex and passed over the migrating region of the complex with the passage of time.

\section{Interpretation on Interaction of Fibrinogen and Heparin}

The area ratio of schlierent patterns of the components was generally discussed on interaction of fibrinogen and heparin according to eq 2. ${ }^{18,19}$ As described elsewhere, the area ratio was evaluated from the ascending schlieren pattern because precipitation occurred in the descending pattern. Since the area ratio of the complex against the free heparin molecules is not changed during migration, the reaction of fibrinogen with heparin seems to have already reached equilibrium before migration.

In a mixture of fibrinogen and heparin, fibrinogen had own peak, the area ratio between any pair of components was not changed during migration, and furthermore, the area of each component was confirmed to be proportional to its concentration. Hence, one can formulate the following equation, assuming the additivity against components.

$$
\frac{A_{\mathrm{Hep}}}{A_{F-H}}=\frac{C_{\mathrm{Hep}}-X}{C_{F-H}}=\frac{\left(C_{\mathrm{Hep}}-X\right) k_{\mathrm{Hep}}}{C_{\mathrm{Fib}} k_{\mathrm{Fib}}+X k_{\mathrm{Hep}}}
$$

where the subcript F-H corresponds to the complex of fibrinogen and heparin, $X$ denotes the concentration of heparin incorporated in the complex, $C_{\mathrm{Hep}}$ and $C_{\mathrm{Fib}}$ are the total concentrations of added heparin and fibrinogen, and $k_{\text {Hep }}\left(=1.22 \times 10^{-3} \mathrm{dl} \mathrm{g}^{-1}\right)^{3}$ and $k_{F i b}$ $\left(=1.80 \times 10^{-3} \mathrm{dlg}^{-1}\right)^{20}$ are the refractive index increment of heparin and fibrinogen, respectively. From the area ratio of free heparin molecules against the complex, the amounts of bound heparin can be calculated by using eq 3 , and are summarized at corresponding concentrations of added heparin in Table II. With increasing concentrations of heparin, the ratio of heparin bound to fibrinogen decreases against concentrations of added heparin but the number of bound heparin molecules per fibrinogen molecule increases.

In kinetic study on the effects of acidic polysaccharides on the interaction of fibrinogen and thrombin, ${ }^{21}$ we have applied the interaction between fibrinogen and acidic polysaccharides to the Freundlich-type adsorption isotherm. That is,

$$
\frac{C_{\mathrm{Hep}}-\left[\mathrm{X}_{\mathrm{e}}\right]}{C_{\mathrm{Fib}}}=k\left(C_{\mathrm{Hep}}-X\right)^{v}
$$

\begin{tabular}{|c|c|c|c|c|c|}
\hline$C_{\mathrm{Fib}}$ & $C_{\text {Hep }}$ & & {$[\mathrm{X}]$} & & Number of bound Hep/Fib \\
\hline $\mathrm{g} \mathrm{dl}^{-1}$ & $\mathrm{~g} \mathrm{dl}^{-1}$ & & $\mathrm{~g} \mathrm{dl}^{-1}$ & & $\mathrm{~mol} / \mathrm{mol}$ \\
\hline 0.375 & 0.50 & 0.695 & 0.0673 & 0.136 & 6.8 \\
\hline 0.375 & 0.375 & 0.510 & 0.0608 & 0.164 & 6.2 \\
\hline 0.375 & 0.25 & 0.324 & 0.0529 & 0.214 & 5.4 \\
\hline
\end{tabular}

Table II. Results from electrophoresis on a complex of fibrinogen and heparin 
where $\left[\mathrm{X}_{\mathrm{e}}\right]$ is the concentration of heparin adsorbed to fibrinogen at adsorption equilibrium, and $k$ and $v$ are constants. The symbol $\left[\mathrm{X}_{\mathrm{e}}\right]$ has substantially the same meaning with $X$ in eq 3 and may be replaced to $X$, written in eq 3. It was found that the Freundlich adsorption isotherm was valid with $v=1 / 3,{ }^{21}$ under experimental conditions of $C_{\mathrm{Fib}}=0.03 \mathrm{~g}$ $\mathrm{dl}^{-1}$ and $C_{\mathrm{Hep}}$ from 0.00147 to $0.0739 \mathrm{~g} \mathrm{dl}^{-1}$ in the same buffer as investigated in this work.

On the basis of eq 4, values for $\log X$ are plotted to numerals for $\log \left(C_{\mathrm{Hep}}-X\right)$ (Figure 3 ). In the plots, a linear relationship was valid, and the exponential numeral was estimated to be 0.305 from the slope. This result indicates that the interaction between fibrinogen and heparin is in obedience to the Freundlich adsorption isotherm. The numeral 0.305 obtained in this electrophoretic work is somewhat smaller than $1 / 3$, possibly because of much higher concentrations investigated here than in our previous work. ${ }^{21}$

Binding between fibrinogen $(F)$ and heparin $(H)$ in the soluble complex $(F-H)$ is regarded as non-covalent but reversible. At equilibrium eq 5 is written with a dissociation constant, $K_{\mathrm{d}}$ of the complex.

$$
F-H \stackrel{K_{\mathrm{d}}}{\rightleftharpoons} F+H
$$

From eq 5 , the following equation, which is used as the Scatchard plot analysis, ${ }^{22}$ is derived.

$$
\frac{[\mathrm{H}]_{\mathrm{b}}}{[\mathrm{H}]_{\mathrm{f}}}=-\frac{1}{K_{\mathrm{d}}}[\mathrm{H}]_{\mathrm{b}}+\frac{n^{\prime}\left[\mathrm{F}_{\mathrm{o}}\right]}{K_{\mathrm{d}}}
$$

where subscripts $b, f$, and o imply reversiblybound, free, and added states, respectively. A constant $n^{\prime}$ is the number of binding sites on fibrinogen. From slope and intercept obtained on plots of numerals for $\left([\mathrm{H}]_{b} /[\mathrm{H}]_{\mathrm{f}}\right)$ against $[\mathrm{H}]_{b}$ values, listed in Table II, both constants were evaluated, i.e., $K_{\mathrm{d}}=7.4 \times 10^{-4} \mathrm{M}$ and $n^{\prime}=4.2$.

A soluble complex, worked on our electrophoretic study, may be drawn as shown in

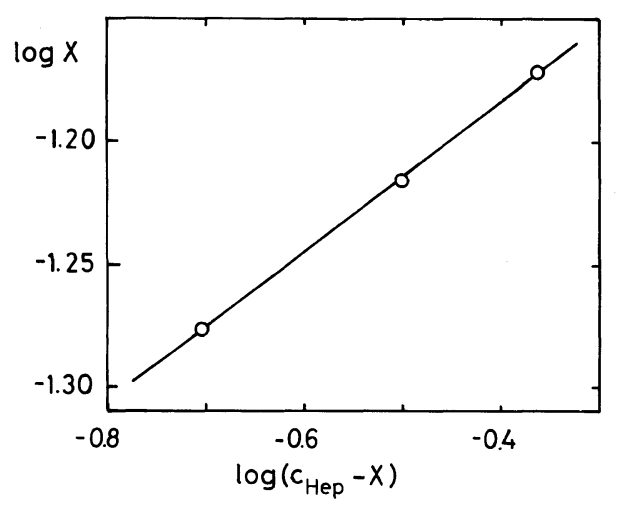

Figure 3. Double logarithmic plots of concentrations $\mathrm{g} \mathrm{dl}^{-1}$ for incorporated heparin in the complex as a function of concentrations $\mathrm{g} \mathrm{dl}^{-1}$ of free heparin, derived from eq 4 .

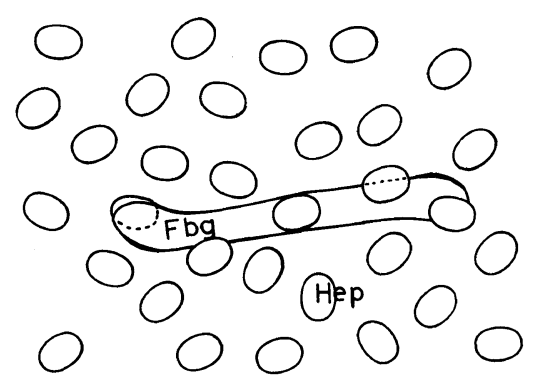

Figure 4. Schematic model for a soluble complex of fibrinogen and heparin, formed under experimental conditions of this work.

Figure 4. Binding number of heparin molecules per one fibrinogen molecule was estimated as 4.3 from our sedimentation study, ${ }^{23}$ while no experimental traces for interaction of fibrinogen and heparin were observed from the viscometric measurement. In Figure 4, heparin, suggested to be substantially flexible, ${ }^{11}$ and to be partially helical, ${ }^{24}$ in solution is drawn as the ellipsoidal shape. Plausible binding sites of heparin on fibrinogen are presumed to be located in the vicinities of hydrolysis sites by thrombin and polymerization sites, because heparin inhibited not only the thrombin reaction ${ }^{21,25}$ to fibrinogen but also retarded the conversion reaction ${ }^{21}$ of fibrinogen to fibrin. In other words, the hydrolysis sites ${ }^{26}$ 


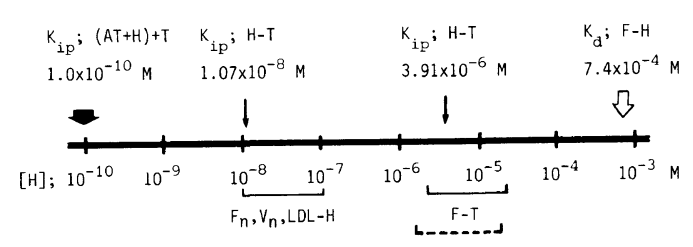

Figure 5. Interactions of heparin with various plasma proteins. Abbreviations; AT, antithrombin III; T, thrombin; $F_{n}$, fibronectin; $V_{n}$, vitronectin; LDL, low density lipoproteins; $K_{\mathrm{ip}}{ }^{33}$ and $K_{\mathrm{mp}},{ }^{34}$ inhibition constant and Michaelis constant $K_{\mathrm{m}}$ obtained from turbidimetry applied to enzyme kinetics.

and polymerization sites on fibrinogen were found to be located on the E and D domains, ${ }^{27}$ i.e., the central domain ${ }^{28}$ and both end regions, ${ }^{29}$ respectively. The structure of fibrinogen is drawn, by taking into consideration one 2-fold axis symmetry, ${ }^{30,31}$ and its twisted major axis in the central domain. ${ }^{32}$

Interactions of heparin with various plasma proteins such as antithrombin III, ${ }^{33}$ thrombin, ${ }^{25}$ fibronectin, ${ }^{2}$ vitronectin, ${ }^{3}$ and low density lipoproteins, ${ }^{35}$ as well as fibrinogen may be summerized as seen in Figure 5 . Heparin is considered to influence on significant inhibitory effects of anticoagulant activities such as the fibrinogen-fibrin conversion, on reactions catalyzed by thrombin and other serine proteases, and on binding with plasma adhesive proteins. Moreover, the complex formation of heparin and antithrombin III inhibits with so small an inhibition constant as to be regraded as an irreversible reaction in plasma. Thus, the formation of a soluble complex of heparin and fibrinogen is considered to be negligibly small amounts at concentrations for heparin administered from 1 to 30 units $\mathrm{ml}^{-1}$ in therapy, corresponding from 0.0067 to $0.2 \mathrm{mg} \mathrm{ml}^{-1}$ of heparin used in this work (drawn by broken line in Figure 5).

\section{REFERENCES}

1. U. Abildgaad, Scand. J. Haematol., 5, 432 (1968).

2. F. Jilek and H. Hörmann, Hoppe-Seyler's Z. Physiol.
Chem., 360, 597 (1979).

3. K. T. Preissner and G. Müller-Berghaus; J. Biol. Chem., 262, 12247 (1987).

4. Y. Fujimura, K. Titani, L. Z. Holland, J. R. Roberts, P. Kostel, Z. M. Ruggeri, and T. S. Zimmerman, $J$. Biol. Chem., 262, 1734 (1987).

5. E. Chargaff, M. Ziff, and D. H. Moore, J. Biol. Chem., 139, 383 (1941).

6. E. Gorter and L. Nanninga, Discuss. Faraday Soc., 13, 205 (1953).

7. P. Porter, M. C. Porter, and J. N. Shanberge, Biochemistry, 6, 1854 (1967).

8. P. Bernfeld, V. M. Donahue, and M. E. Berkowitz, J. Biol. Chem., 226, 51 (1957).

9. H. C. Godal, Scand. J. Clin. Lab. Invest., 12, 56 (1960).

10. H. Sato, E. Nakanishi, and A. Nakajima, Int. J. Biol. Macromol., 3, 66 (1981).

11. S. E. Lasker and S. S. Stivala, Arch. Biochem. Biophys., 115, 360 (1966).

12. N. E. Slathakis and M. W. Mosesson, J. Clin. Invest., 60, 855 (1977).

13. E. Mihalyi, Biochemistry, 7, 208 (1970).

14. H. B. Nader, N. M. McDuffie, and C. P. Dietrich, Biochem. Biophys. Res. Commun., 57, 488 (1974).

15. S. E. Lasker, Fed. Proc., 36, 92 (1977).

16. L. B. Jaques, Can. J. Physiol. Pharmacol., 46, 351 (1968).

17. S. Sasaki and H. Noguchi, J. Gen Physiol., 43, 1 (1959).

18. T. E. Thompson and W. N. McKernan, Biochem. J., 81, 12 (1961).

19. H. Noguchi, Biochem. Biophys. Acta, 22, 459(1956).

20. R. Sowinski, L. Oharenko, and V. L. Koenig, J. Am. Chem. Soc., 81, 6193 (1959).

21. E. Nakanishi, H. Sato, and A. Nakajima, Polym. Bull., 3, 655 (1980).

22. G. Scatchard, Ann. N. Y. Acad.Sci., 51, 660 (1949).

23. E. Nakanishi, H. Sato, and A. Nakajima, submitted to Polym. Bull.

24. S. Yamaguchi, H. Hayashi, F. Hamada, and A. Nakajima, Biopolymers, 23, 995 (1984).

25. H. Sato, A. Nakajima, and T. Shimohira, Thromb. Res., 39, 549 (1985).

26. V. Nussenzweig and M. Seligmann, Rev. Hématol., 15, 451 (1960).

27. B. Blombäck and I. Yamashina, Ark. Kemi, 12, 299 (1958).

28. J. N. Telford, J. A. Nagy, P. A. Hatcher, and H. A. Scheraga, Proc. Natl. Acad. Sci. U.S.A., 77, 2372 (1980).

29. S. A. Olexa and A. Z. Budzynski, J. Biol. Chem., 256, 3544 (1981).

30. B. Blombäck, B. Hessel, M. Okada, and N. Egberg, Ann. N. Y. Acad. Sci., 370, 536 (1981).

31. J. W. Weisel, Thromb. Res., 48, 615 (1987).

32. J. W. Weisel, C. Nagaswami, and L. Makowski, Proc. 
Soluble Complex of Heparin and Fibrinogen

Natl. Acad. Sci. U.S.A., 84, 8991 (1987).

33. H. Sato and A. Nakajima, Thromb. Res., 37, 327 (1985).

34. H. Sato and A. Nakajima, Thromb. Res., 35, 133
(1984).

35. A. D. Cardin, R. L. Jackson, B. Elledge, and D. Feldhake, Int. J. Biol. Makromol., 11, 59 (1989). 